\title{
Classic Kaposi Sarcoma in the United States over the last two decades: A clinicopathologic and molecular study of 438 non-HIV-related Kaposi Sarcoma patients with comparison to HIV-related Kaposi Sarcoma
}

\author{
Kim M Hiatt ${ }^{1}$, Ann M Nelson², Jack H Lichy² and Julie C Fanburg-Smith² \\ ${ }^{1}$ Dermatopathology, University of Arkansas for Medical Sciences, Little Rock, AR, USA and ${ }^{2}$ Departments of \\ Infectious Disease, Molecular, and Soft Tissue/Orthopaedic Pathology, Armed Forces Institute of Pathology, \\ Washington, DC, USA
}

\begin{abstract}
Classic Kaposi sarcoma is rare and occurs predominantly in Mediterranean and Middle Eastern men. Since the emergence of acquired immune deficiency syndrome (AIDS)-related Kaposi sarcoma, the incidence, clinicopathologic features, and molecular human herpesvirus 8 (HHV-8) association of American Classic Kaposi Sarcoma has not been fully explored. This study compares Classic Kaposi Sarcoma to AIDS-related Kaposi Sarcoma over the same two decade time period. There were $\mathbf{4 3 8}$ histologically and clinically confirmed Classic Kaposi Sarcoma patients. The ethnic/racial distribution included Caucasian/American (56\%), Mediterranean (22\%), South American Hispanic (18\%), Black (10\%), western European (4\%), Middle East (4\%), Scandinavian (2\%), and other (2\%). Classic Kaposi Sarcoma was more common in men, 7:1, with a mean age of 74 years. The lesions presented in the lower extremity $(69 \%)$, in the nodular stage $(83 \%)$, and HHV-8 was detected by PCR in 40/41 randomly selected cases. A second, non-Classic Kaposi Sarcoma, malignancy was present in $42 \%(n=45)$ of the 108 Classic Kaposi Sarcoma patients with complete clinical information, $73 \%$ (33 patients) with a higher incidence over the general population. Follow-up of $<1-19$ years (mean $=4.8$ years) revealed that $24 \%$ of patients died of second malignancy, $22 \%$ died of other medical conditions, $2 \%$ died of treatment-related complications, and $2 \%$ patients died of widespread disease. Thirty-five percent are alive with no evidence of disease and $15 \%$ with persistent disease. Human immunodeficiency virus-related Kaposi Sarcoma was observed in 354 cases. There was a male predominance and more aggressive behavior, with higher rates of visceral and disseminated disease. While Classic Kaposi Sarcoma in the United States is an indolent disease and rarely accounts for patient demise, predominantly affecting Caucasian/American males on the lower extremity in the nodular phase, it more importantly may denote an underlying other malignancy. Current PCR probes detect HHV-8 in 98\% of Classic Kaposi Sarcoma cases. In comparison, AIDS-related Kaposi Sarcoma is predominately multicentric, visceral, and disseminated, with more aggressive behavior.

Modern Pathology (2008) 21, 572-582; doi:10.1038/modpathol.2008.15; published online 28 March 2008
\end{abstract}

Keywords: classic Kaposi sarcoma; United States; 1980-2000; AIDS-related Kaposi sarcoma; pathology; HHV-8

Correspondence: Dr JC Fanburg-Smith, MD, Orthopaedic and Soft Tissue Pathology Department, Armed Forces Institute of Pathology, Building 54, Department of Soft Tissue Pathology, Room G090, 14th Street and Alaska Avenue, NW, Washington, DC 20306-6000, USA.

E-mail: Fanburg@afip.osd.mil

The opinions and assertions are the expressed views of the authors and are not to be construed as official or as a reflection of the views of the Department of Army or Defense. This was presented in part as an abstract at the USCAP.

Received 07 November 2006; revised and accepted 25 June 2007; published online 28 March 2008
Classic Kaposi Sarcoma is traditionally known as an indolent disease in elderly men of Mediterranean and Middle Easternern descent. With the emergence of acquired immune deficiency syndrome (AIDS) in the United States in the early 1980s, Kaposi sarcoma came to the forefront, because of its association with human immunodeficiency virus positive $(\mathrm{HIV}+)$ individuals, particularly in certain risk groups. Cox and Helwig reported on 50 cases of Kaposi Sarcoma from our institute in 1959. ${ }^{1}$ Those cases included 8 Italians and 11 Africans, and thus likely represented 
a combination of classic and endemic forms, as the AIDS epidemic had not yet begun. In 1999, Smith et $a l^{2}$ reported on 250 women with all subsets of Kaposi Sarcoma, including women from the United States as well as other countries. To our knowledge, there have been no recent large studies on Classic Kaposi Sarcoma in the United States.

\section{Materials and methods}

The Soft Tissue Pathology registry at the Armed Forces Institute of Pathology was searched for 'Classic Kaposi Sarcoma' patients. Although Classic Kaposi Sarcoma is known to occur in younger patients, to ensure the exclusion of patients who may not yet be seropositive for HIV, only patients over the age of 65 years at diagnosis were chosen for this study. From a cohort of 682 patients with 752 Kaposi Sarcoma lesions, slides were available and diagnostic of Classic Kaposi Sarcoma in 438 patients. All patients known to be HIV + or have high-risk activity, based on the submitted report or discussion with the clinician, were excluded from the Classic Kaposi Sarcoma group (9/682).

Information on the AIDS-related Kaposi Sarcoma patients was obtained from the AIDS Registry at the Armed Forces Institute of Pathology. These actually included three patients over the age of 65 who were known to be HIV +. Additionally, patients from Africa (25/682) were excluded to avoid confounding the data with specimens that possibly represented endemic/epidemic Kaposi Sarcoma. None of the Classic Kaposi Sarcoma patients were known to be transplant recipients and none were reported to be 'iatrogenic' or chemotherapy/immunosuppressive therapy induced. Kaposi Sarcoma diagnosis was made using previously established criteria. $^{3}$

Tumor registries, physicians, and patients were systematically contacted to obtain information regarding age, gender, reported nationality or ethnicity, concurrent malignancies, status of the patient as well as size, location, multicentricity, and dissemination of the Kaposi Sarcoma. Except for the data on associated malignancies, which were not available for the AIDS-related group, all data were compared to a group of AIDS-related Kaposi Sarcoma patients $(n=354)$ at our institute during the same time period. Kaposi Sarcoma was classified as solitary based on clinical presentation of a single lesion, multifocal when more than one lesion involving the same lymphatic flow was present, multicentric when more than one lesion was present that involved different lymphatic drainages, and disseminated when multiple visceral sites were involved. The contributing pathologist's diagnosis, when known, was recorded for the Classic Kaposi Sarcoma patients; this information was not available for the AIDS-related patients. Forty-one lesions, randomly chosen and representing all stages of Classic Kaposi Sarcoma development from both

genders, were evaluated for human herpesvirus 8 (HHV-8) status. The AIDS-related Kaposi Sarcoma cases were not evaluated for HHV-8 positivity.

The Surveillance, Epidemiology and End Results (SEER) Cancer Statistic Review ${ }^{4}$ from National Institute of Health, for the population over 65 years old, monitoring cancer incidence in approximately $10 \%$ of the US population since 1973 , was used to compare the expected incidence of cancers in the general population to the incidence of associated malignancies in this cohort of Classic Kaposi Sarcoma patients.

\section{Polymerase Chain Reaction}

DNA was extracted from six 6-m sections of each block by deparaffinization with Hemo-De followed by protease $\mathrm{K}$ digestion, extraction with phenol/ chloroform, and ethanol precipitation, as previously described by Lichy et al..$^{5}$ The probe and primer sequences are listed in Table 1.

\section{Results}

\section{Patient Demographics}

The original patient list included 446 males and 183 females, with a ratio of 2.4 males to 1 female. The current study group of 438 patients with available diagnostic material included 385 men $(385 / 446=86 \%$ of the data bank male patients with classic Kaposi Sarcoma) and 53 women (53/ $183=29.5 \%$ of the data bank of female patients with classic Kaposi Sarcoma), 7 males to 1 female. Available data from 354 AIDS-related Kaposi Sarcoma patients diagnosed at our institution between 1980 and 2000 were compared with the Classic Kaposi Sarcoma cases. Known risk factors for the AIDS-related cases $(n=97)$ are the following: 54 $(56 \%)$ homosexual/bisexual, $12(12 \%)$ intravenous drug users, $21(22 \%)$ African (12 of 13 females were from Africa), 4 (4\%) transfusion related, and 5 (5\%) other. The male:female ratio for the AIDS-related

Table 1 HHV-8 probe and primer sequences

HHV-8 (putative minor capsid protein) (11)

$\mathrm{KS}_{3} 30_{233}$

(forward):

$\mathrm{KS}_{3} 30_{233}$

(reverse):

$\mathrm{KS}_{330} \mathrm{O}_{233}$

(probe):

HER2-977F

(forward):

HER2-1120R

(reverse):

HER2-1012T

(probe):
5'-AGCCGAAAGGATTCCACCAT-3'

5'-TCCGTGTTGTCTACGTCCAG-3'

5'-TGCAGCAGCTGTTGGTGTACCACAT-3'

5'-ATGCAGATTGCCAAGGTATGC-3'

5'-GGAAGCACCCATGTAGACCTTCT-3'

5'-(VIC)CCGGAGCAAACCCCTATGTCCACAA (TAMRA)-3' 
Kaposi Sarcoma was 29:1. The age of the Classic Kaposi Sarcoma patients ranged from 65 years, by our study-defined inclusion criteria, to 94 years (median, 74 years). In comparison, AIDS-related Kaposi Sarcoma patients ranged from 13 to 81 years (median, 36 years). Only three known AIDS-related Kaposi Sarcoma patients were over the age of 65 during this two-decade period. Known demographics for Classic Kaposi Sarcoma patients and AIDS-related Kaposi Sarcoma patients are compared in Table 2.

The 438 Classic Kaposi Sarcoma patients had 486 lesions available for review: $91 \%$ of patients had one lesion available for evaluation, $6 \%$ of the patients had two lesions evaluated, $2 \%$ of the patients had three lesions, and four had seven lesions. By report, $77 \%$ of the Classic Kaposi Sarcoma patients had solitary lesions, $22 \%$ had multifocal or multicentric disease, and $<1 \%$ had disseminated disease. In comparison, the AIDS-related Kaposi Sarcoma had a higher percentage of multifocal/multicentric (78\%) and disseminated disease (6\%, Table 3$)$. The locations for Classic Kaposi Sarcoma and AIDS-related Kaposi Sarcoma tumors are compared in Table 4.

The most common location for all groups was the lower extremity, particularly the distal lower extremity. In comparison, the predominant locations of the AIDS-related Kaposi Sarcoma had a higher percentage of multifocal/multicentric (78\% AIDSrelated compared to 22\% Classic Kaposi Sarcoma) and disseminated disease (6\% AIDS-related compared to $<1 \%$ of the Classic Kaposi Sarcoma patients). The average size of the 161 Classic Kaposi Sarcoma lesions with size information available was $1.2 \mathrm{~cm}$ (range $0.2-15 \mathrm{~cm}$ ).

\section{Microscopic}

The Classic Kaposi Sarcoma lesions represented all stages of Kaposi Sarcoma: patch $(n=44,9 \%$; Figure 1), plaque (Figure 2), one with ulceration $(n=39$, $8 \%$ ), nodular (Figure 3), and 4 with multinodularity $(n=390,80 \%)$. The nodular lesions were additionally noted to be pedunculated $(67 / 390=17 \%)$, ulcerated $(59 / 390=15 \%)$, or pedunculated and ulcerated, one with central necrosis (90/ $390=23 \%)$. There were seven deep dermal and one subcutaneous lesion (Figure 4), all of which were nodular. The remaining skin lesions were in the superficial dermis. The lesions seen on the seven GI biopsies and six lymph node specimens were diffuse and were not included in the patch, plaque, or nodular classification. All lesions showed typical histologic features. The early lesions had a proliferation of miniature vessels surrounding larger ecstatic vessels. The later lesions had spindled cells forming vascular slits with extravasated red blood cells, a variable lymphoplasmacytic infiltrate, hemosiderin-laden macrophages, distinctive cytoplasmic borders, and cytoplasmic and extracellular hyaline globules, particularly in plaque and nodular
Table 2 Nationality/racial backgrounds of CKS compared to AIDS-KS patients at our institution between 1980 and 2000

\begin{tabular}{lcc}
\hline Background & $\begin{array}{c}\text { Number of CKS } \\
\text { patients (\%), } \\
\mathrm{n}=221\end{array}$ & $\begin{array}{c}\text { Number of } \\
\text { AIDS-related KS } \\
\text { patients (\%), } \\
\mathrm{n}=199\end{array}$ \\
\hline Caucasian & $85(38)$ & $97(49)$ \\
Mediterranean & $49(22)$ & 0 \\
Hispanic & $39(18)$ & $20(10)$ \\
Black & $22(10)$ & $59(30)$ \\
W. European & $9(4)$ & 0 \\
Middle East & $8(4)$ & 0 \\
Scandinavian & $4(2)$ & 0 \\
African & 0 & $21(11)$ \\
Asian & 0 & $2(1)$ \\
Other & $5(2)$ & 0
\end{tabular}

Nationality/racial background of CKS patients $(n=221)(\%)$

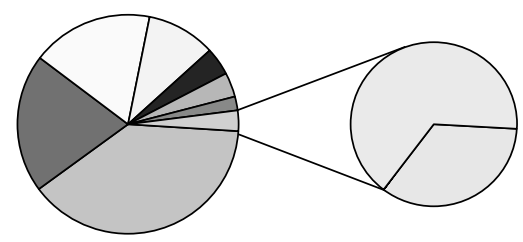

$\square$ Caucasian

$\square$ Italian

$\square$ Hispanic

$\square$ Black

- W. European

$\square$ Middle East

$\square$ Scandinavian

$\square$ Mediterranean

- African

Asian

Other

Nationality/racial background of CKS and AIDS-KS patients

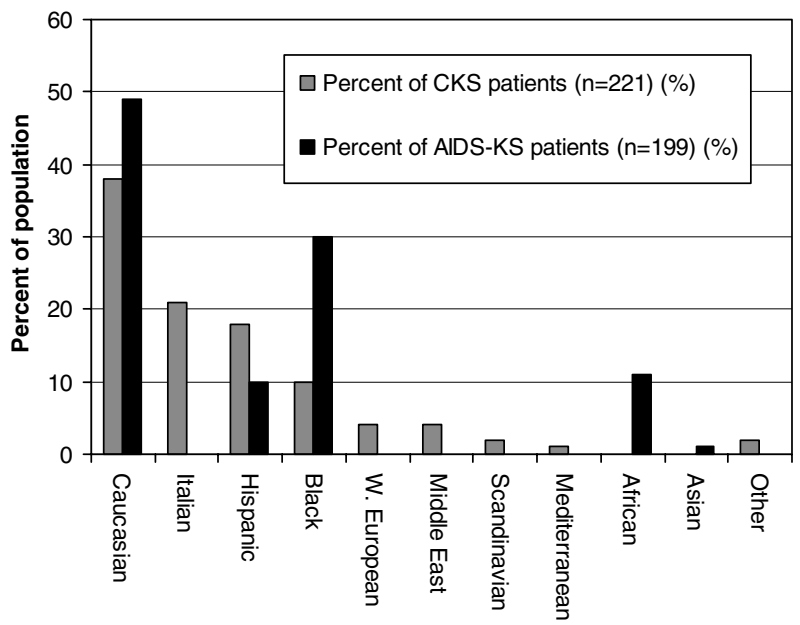

phase. There was an absence of significant pleomorphism or mitotic activity.

The contributing pathologist's diagnosis $(n=257)$ for the Classic Kaposi Sarcoma cases, considering mostly vascular, fibroblastic, or neural lesions, are listed in Table 5. 
Table 3 Focality of lesions in CKS patients compared to AIDS-KS patients

Focality of lesions in CKS compared to AIDS-KS patients

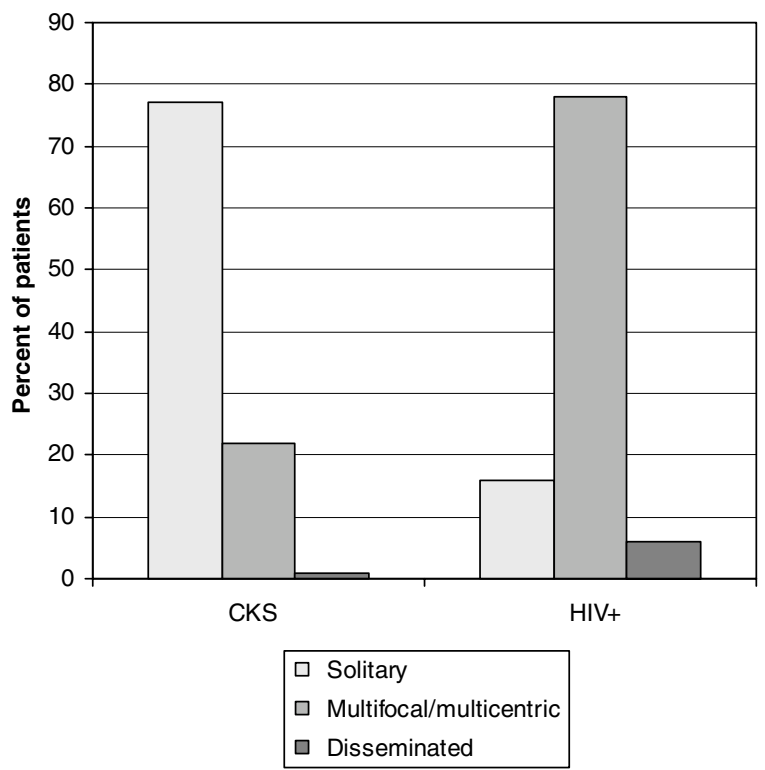

Table 4 Comparison of sites of involvement: classicks to HIV+KS

\begin{tabular}{lcc}
\hline Site & $\begin{array}{c}\text { Number of patients } \\
\text { with CKS at our } \\
\text { institution from } \\
1980 \text { to } 2000 \\
n(\%)\end{array}$ & $\begin{array}{c}\text { Number of patients } \\
\text { with HIV positive } \\
\text { related KS at our } \\
\text { institution } \\
\text { from } 1980 \text { to 2000 } \\
n(\%)(\mathrm{n}=251)^{*}\end{array}$ \\
\hline Lower extremity & $335(69)$ & $76(21)$ \\
Upper extremity & $68(14)$ & $47(13)$ \\
Head and neck & $23(5)$ & $18(5)$ \\
Penis & $15(3)$ & $5(1)$ \\
Trunk & $11(2)$ & $44(12)$ \\
Gastrointestinal & $6(1)$ & $19(5)$ \\
Lymph node & $6(1)$ & $40(12)$ \\
Conjunctiva & $1(<1)$ & $3(1)$ \\
Not specified & $8(2)$ & 0 \\
Disseminated & $2 *$ & $21(6)$ \\
Lung & 0 & $25(7)$ \\
Oral/salivary*** & $9(2)$ & $37(11)$ \\
Ano-rectal*** & $1(<1)$ & $11(3)$ \\
Other & $1(<1)$ & $3(1)$ \\
\hline
\end{tabular}

\section{Molecular Analysis}

The HHV-8 evaluation on Classic Kaposi Sarcoma patients from AFIP revealed that 40 of 41 cases $(40 / 41=98 \%)$ were positive (Figure 5) and 1 case was negative for HHV-8 by PCR.

\section{Follow-up and Associated Malignancies}

Clinical follow-up of 108 Classic Kaposi Sarcoma patients revealed that $42 \%(n=45)$ had associated malignancies: prostate carcinoma $(n=11)$, basal cell carcinoma (BCC) $(n=11)$, lung carcinoma $(n=6)$, multiple myeloma $(n=4)$, malignant lymphoma $(n=4)$, colorectal carcinoma $(n=3)$, squamous cell carcinoma of the skin $(n=3)$, laryngeal carcinoma $(n=2)$, transitional cell carcinoma of the bladder $(n=2)$, and one each of renal cell carcinoma, oral squamous cell carcinoma, malignant melanoma, gastric carcinoma, pancreatic carcinoma, and breast carcinoma. These include seven patients that had two other primary malignancies. Of those, one patient had transitional cell carcinoma and prostate carcinoma; the other six had BCC and either squamous cell carcinoma $(n=3)$, lung carcinoma $(n=2)$, or prostate carcinoma $(n=1)$. One patient had associated benign lymphangiomatosis and one had benign thymoma. None of the patients had central nervous system neoplasms, female genital tract neoplasms, or other sarcoma. Although the specific data for associated malignancies in the AIDS-related Kaposi Sarcoma group were not available, many of those patients had associated anal carcinoma and lymphoma and one patient developed angiosarcoma. Thirty-three of 45 patients $(73 \%)$ had a malignancy over the normal US population incidence. The associated malignancies of Classic Kaposi Sarcoma patients and comparison to the general populations' incidence of cancers as expected from the SEER study are found in Table 6 .

Over follow-up periods ranging from $<1$ to 19 years, with a mean of 4.8 years, $22 \%(n=24)$ of the Classic Kaposi Sarcoma patients died of other medical conditions, predominantly respiratory and cardiovascular disease, $24 \%(n=26)$ of other malignancies, $2 \%(n=2)$ of treatment-related complications, one of radiation complications and one of sepsis after bowel perforation during biopsy of a lesion, and $2 \%$ from widespread visceral Kaposi Sarcoma. Fifteen percent $(n=16)$ of the patients are alive with disease, two with a second malignancy, and $35 \%(n=38)$ are alive and free of disease, over a mean interval of 6 years (range 1-19 years, Table 7). Seventeen of the disease-free patients have second malignancies. Details of post-surgical treatment, including adjuvant therapy, are unavailable. Specific follow-up for the AIDS-related Kaposi Sarcoma cases was unknown; when present, disseminated disease led to the patient demise.

\section{Discussion}

Kaposi Sarcoma is a solitary or multifocal lymphatic tumor, initially described as Classic Kaposi Sarcoma almost 130 years ago, in elderly men of Middle Eastern and Mediterranean descent. ${ }^{6,7}$ In North America, Classic Kaposi Sarcoma is rare with an incidence of $2.6-4.1 /$ million men and $0.6-0.9 /$ million women ${ }^{4}$ compared with incidences as high as $50 /$ million men and $28 /$ million women in rural areas of Italy ${ }^{8}$ and $16.9 /$ million men and 6.3/million women in Israel. ${ }^{9}$ In addition to this classic variant 

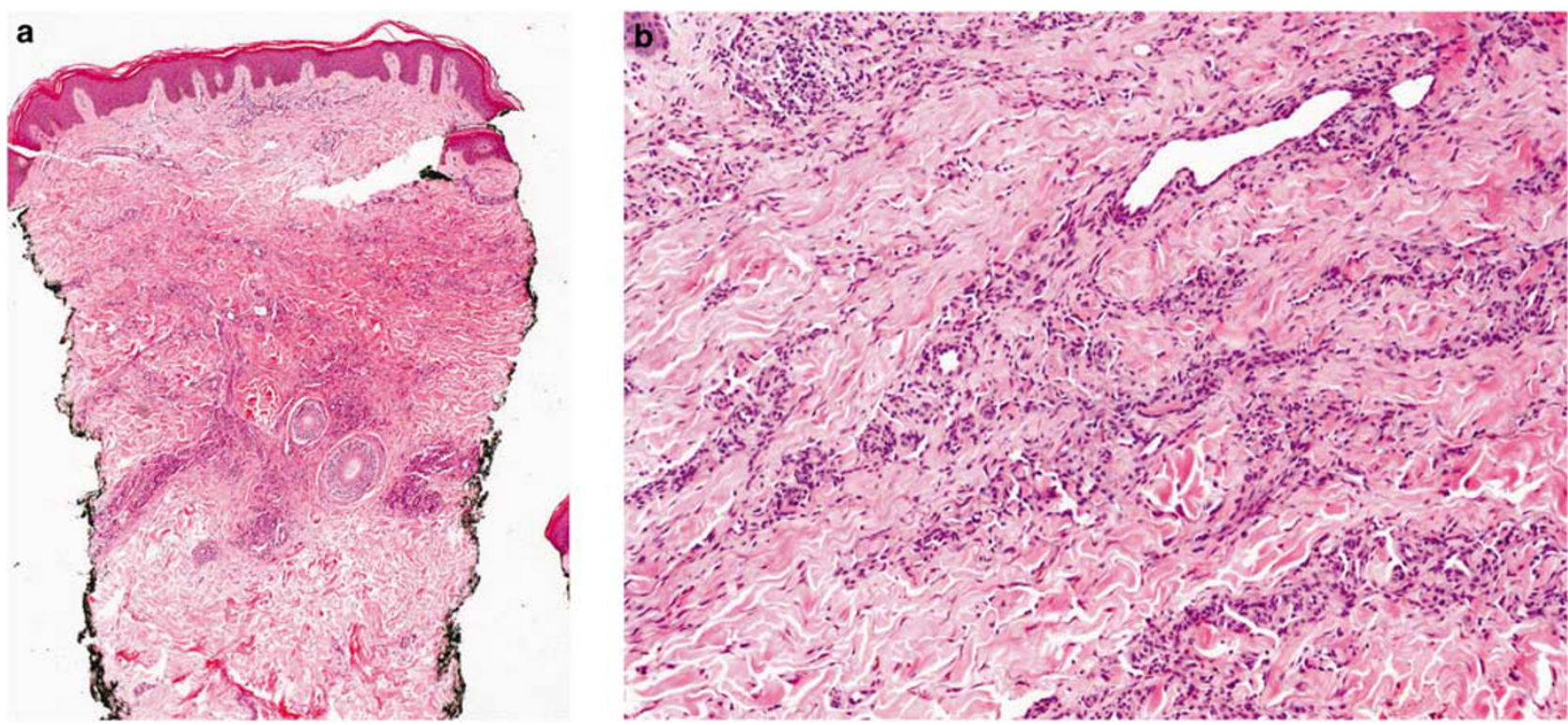

Figure 1 Patch phase of Classic Kaposi Sarcoma with plump epithelioid to spindled perivascular proliferations and a lymphoplasmacytic infiltrate, at lower (a) and higher (b) magnification.

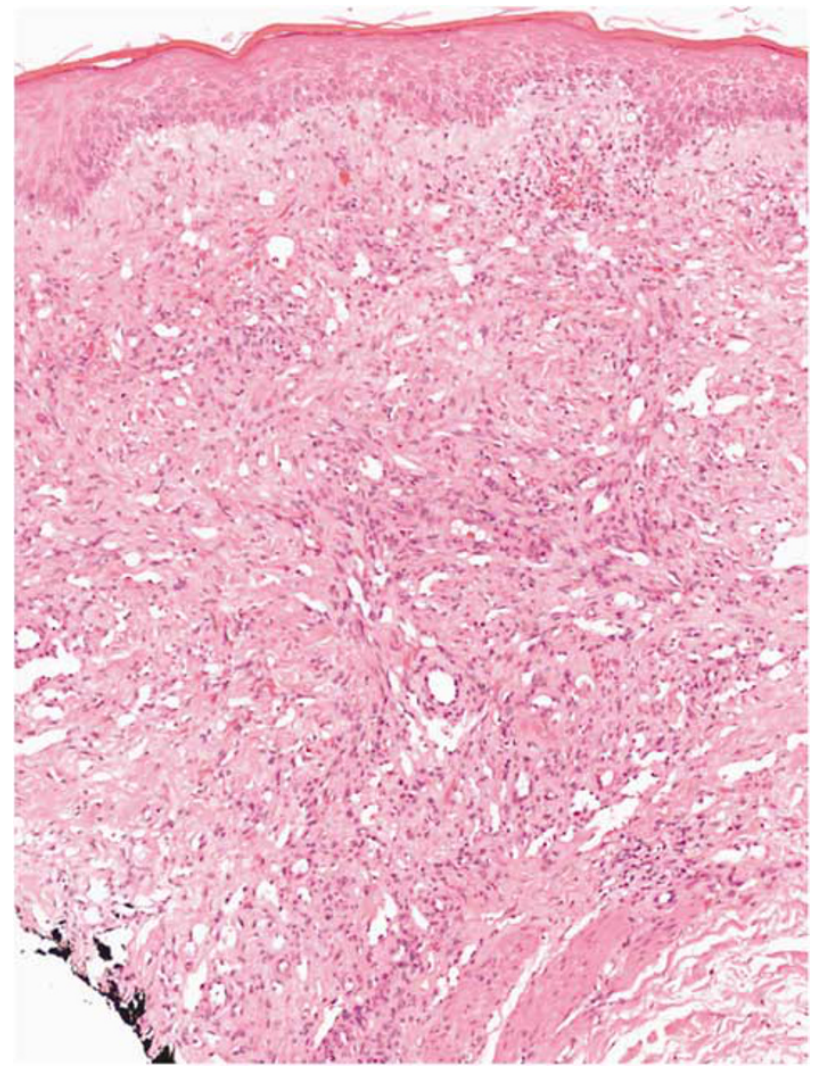

Figure 2 Plaque phase of Classic Kaposi Sarcoma where the perivascular spindled cells with extravasated erythrocytes and hemosiderin have coalesced to form a plaque.

of Kaposi Sarcoma, the disease is endemic in parts of Africa, and present in association with AIDS and transplant/immunosuppression; these later variants are excluded from the present review. No recent report has evaluated the demographics and clinical presentations of Classic Kaposi Sarcoma patients in the United States and compared these data to AIDSrelated Kaposi Sarcoma patients in the United States. Furthermore, although all types of Kaposi Sarcoma have shown the presence of HHV-8, a gamma-herpes virus, ${ }^{10-12}$ no previous large group of Classic Kaposi Sarcoma has been systematically studied for HHV-8. The current study represents the largest reported group of Classic Kaposi Sarcoma in North America and is notable for excluding AIDSrelated Kaposi Sarcoma, endemic Kaposi Sarcoma (African), and transplant-related Kaposi Sarcoma or that caused by other immunosuppression (iatrogenic Kaposi Sarcoma).

Classic Kaposi Sarcoma is traditionally known as an indolent disease presenting in the lower extremities of adult men of Mediterranean and Middle Eastern descent. The lesions are known to coalesce and progress proximally over the course of many years. Histologically, Classic Kaposi Sarcoma is indistinguishable from other forms of Kaposi Sarcoma, which all characteristically evolve through a continuum of features classified as patch, plaque, and nodular stages. The histologic features of all forms of Kaposi Sarcoma show irregularly shaped, slit-like vascular spaces lined by plump, relatively uniform spindled cells with well-defined cytoplasmic borders, extravasated erythrocytes, a variable lymphoplasmacytic infiltrate, hemosiderin-laden macrophages, and intracellular and extracellular eosinophilic hyaline globules. ${ }^{3}$ These globules, which are periodic acid Schiff positive, diastase resistant and may be sparse to non-existent in patch stage lesions, represent erythrocyte breakdown products. ${ }^{13}$ 

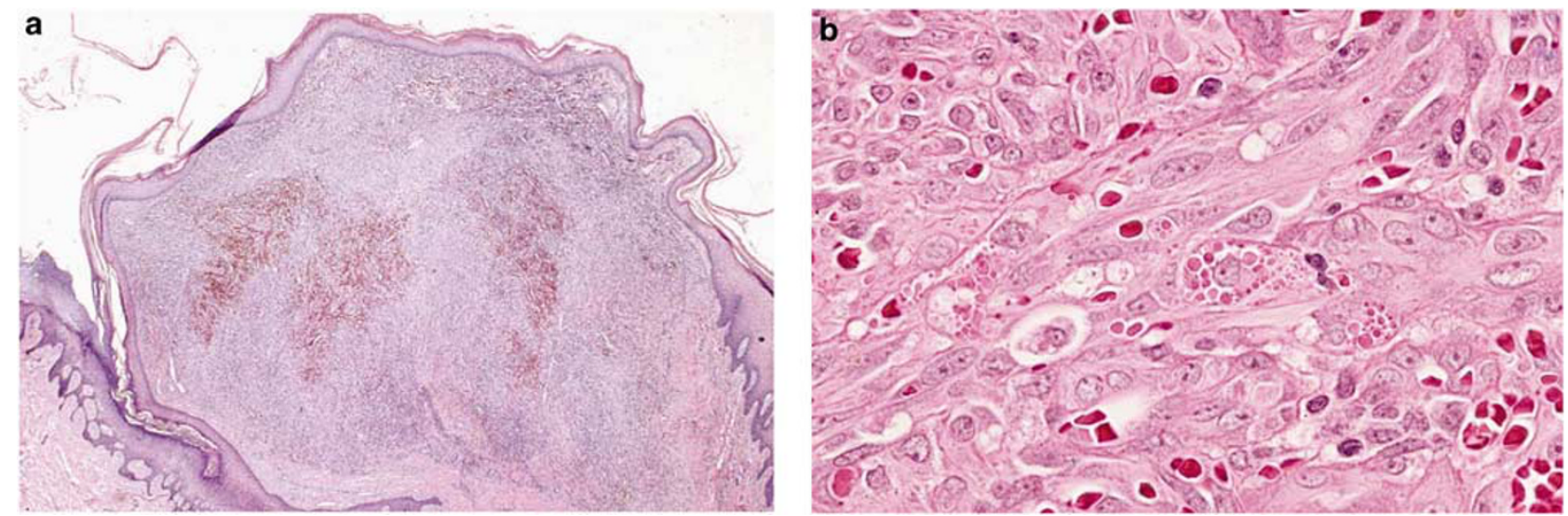

Figure 3 Nodular phase of Classic Kaposi Sarcoma; note the pedunculated growth pattern (a); many of these nodular lesions were also ulcerated. The cytoplasmic hyaline globules are depicted at higher magnification (b).

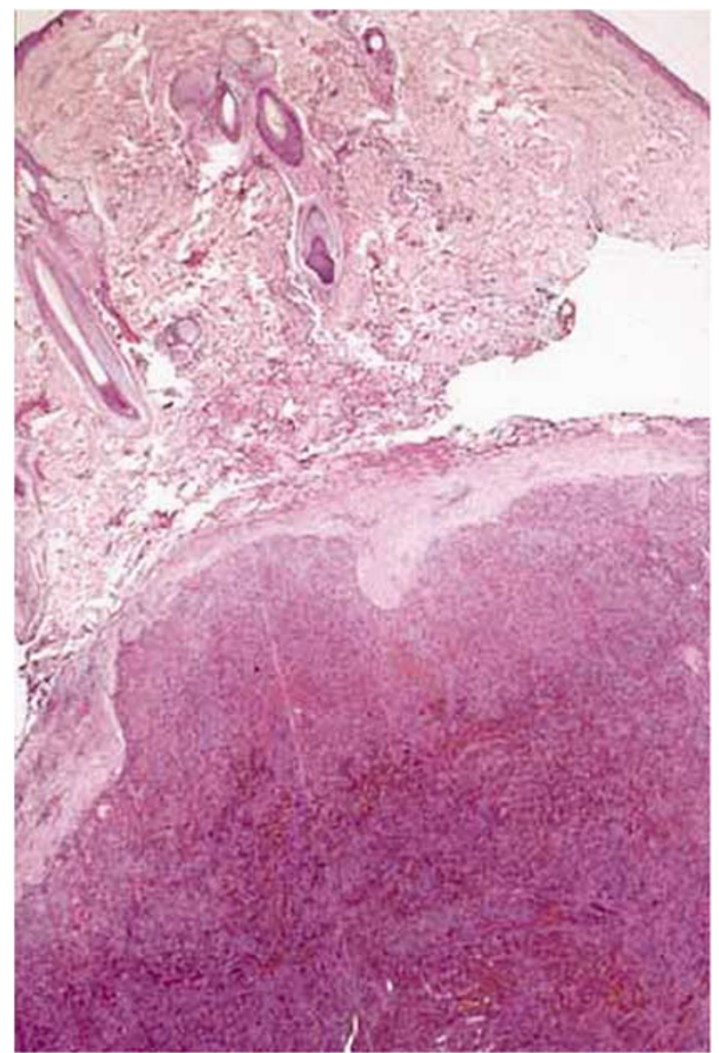

Figure 4 Example of the one subcutaneous Classic Kaposi Sarcoma; the other skin lesions were predominantly dermal based.

Our series identifies Classic Kaposi Sarcoma in the United States as a disease predominantly of Caucasian Americans, followed by Mediterraneans, Hispanics, and Black Americans. As tumor registries and patient questionnaires consider inquiring into the racial background an unethical pursuit, there was often insufficient history to further divide the group of Caucasian Americans. Therefore, it is unclear whether this ethnic background varies significantly from those lesions seen in Mediterra- nean and Middle Eastern men, as originally described by Moriz Kaposi in 1872. ${ }^{7}$ The comparison AIDS-related Kaposi Sarcoma group had a higher number of Caucasian American, Black American, African, and Asian patients than the Classic Kaposi Sarcoma group, reflecting their risk factors and places of living. The Classic Kaposi Sarcoma male:female ratio is 2.4:1 compared to 29:1 for the AIDS-related Kaposi Sarcoma group. This Classic Kaposi Sarcoma ratio compared similarly to that previously published data. ${ }^{14-17}$

While Classic Kaposi Sarcoma lesions in this cohort were generally manifest in the lower extremities, followed by the upper extremities and head and neck, our study reveals less upper extremity, lymph node, and visceral sites than previously reported for Classic Kaposi Sarcoma. ${ }^{1,9,15,17,18}$ The findings of a large number $(n=15)$ of Classic Kaposi Sarcoma in the penis in the current study may relate to the previous identification of HHV-8 in semen, even in normal individuals. ${ }^{19}$ In comparison, the AIDS-related Kaposi Sarcoma had fewer lower extremity lesions and included more sites highly predictive of HIV infection: that is oral and anogenital.

The current study found that $42 \%$ of the Classic Kaposi Sarcoma patients with complete follow-up data available had associated second primary malignancies, a higher occurrence than previously reported in the literature, 9-37\%..$^{1,15-17,20-22}$ Iscovich et $a l^{23}$ report Classic Kaposi Sarcoma as a primary neoplasm in $16.6 \%$ of patients ${ }^{9}$ and as a second primary neoplasm in $8.3 \%$. Although, Classic Kaposi Sarcoma is reportedly more commonly a primary than a secondary neoplasm,,$^{9,23}$ a temporal relationship was not investigated in this cohort. However, information was obtained in several cases indicating Classic Kaposi Sarcoma arose subsequent to the other malignancy, offering the suggestion that the initial primary neoplasm played a role in the development of Classic Kaposi Sarcoma. This correlates well with hypothesis that HHV-8 has a role in the etiology of Classic Kaposi Sarcoma as 
Table 5 Submitting contributors' diagnoses

\begin{tabular}{|c|c|c|}
\hline Contributor's diagnosis & $\mathrm{n}$ & $\%$ \\
\hline Kaposi sarcoma considered (s/o, c/w, r/o) & 144 & 56 \\
\hline Vascular neoplasm: & & 31.6 \\
\hline $\begin{array}{l}\text { Hemangioma (12), capillary hemangioma } \\
\text { (5), pyogenic granuloma (30), epitheliod } \\
\text { hemangioma (1) }\end{array}$ & 52 & \\
\hline Atypical vascular proliferation (16) & 16 & \\
\hline $\begin{array}{l}\text { Endothelial cell proliferation (1), } \\
\text { hemangioendothelioma (2) }\end{array}$ & 3 & \\
\hline Angiosarcoma (5), hemangiosarcoma (3) & 8 & \\
\hline \multicolumn{3}{|l|}{ Smooth muscle neoplasm: } \\
\hline Leiomyoma (4)/smooth muscle tumor (2) & 6 & 3.9 \\
\hline Leiomyosarcoma (3)/angioleiomyosarcoma (1) & 4 & \\
\hline \multicolumn{3}{|l|}{ Fibroblastic neoplasm: } \\
\hline Hemangiopericytoma & 2 & 9.4 \\
\hline Fibrous histiocytoma (9)/dermatofibroma (6) & 15 & \\
\hline DFSP & 6 & \\
\hline $\mathrm{MFH}$ & 3 & \\
\hline \multicolumn{3}{|l|}{ Spindle cell, not otherwise specified: } \\
\hline $\begin{array}{l}\text { Atypical spindle cell lesion (6)/spindle cell } \\
\text { lesion (5)/vascular spindle cell lesion (5) }\end{array}$ & 16 & 6.2 \\
\hline Malignant spindle cell lesion & 5 & 1.9 \\
\hline $\begin{array}{l}\text { Reactive lesions: reactive (4), granulation } \\
\text { tissue (3), pseudotumor (1), inflammatory } \\
\text { angiomatous nodule (1) }\end{array}$ & 9 & 3.9 \\
\hline Granuloma & 1 & \\
\hline $\begin{array}{l}\text { Nerve sheath lesions: neurofibroma (3), } \\
\text { schwannoma (1) }\end{array}$ & 4 & 1.5 \\
\hline $\begin{array}{l}\text { Other dermal lesions: stasis dermatitis ( } 3 \text { ), } \\
\text { acroangiodermatitis of Mali (1) }\end{array}$ & 4 & 1.5 \\
\hline $\begin{array}{l}\text { Melanoma (3), spindle cell squamous cell } \\
\text { carcinoma (2) }\end{array}$ & 5 & 1.9 \\
\hline
\end{tabular}

c/w, consistent with; DFSP, dermatofibrosarcoma protuberans; MFH, malignant fibrous histiocytoma; r/o, rule out; s/o, suggestive of.

well as in the development of second malignancies. $^{9,21}$ Likewise, the Classic Kaposi Sarcoma may be a sign of underlying malignancy.

The Classic Kaposi Sarcoma population in this study had an increased incidence of multiple myeloma and non-Hodgkin's lymphoma compared to that expected based on SEER data. ${ }^{4}$ While a controversial increased incidence of multiple myeloma and other hematopoietic neoplasms in Classic Kaposi Sarcoma has been extensively reported in the literature, ${ }^{14,16,18,21-29}$ the suggested link between HHV-8 and multiple myeloma ${ }^{30}$ supports an increase, such as noted in our study, in multiple myeloma in Kaposi Sarcoma patients. An increased incidence of other hematopoietic neoplasms was also observed in our cohort. However, none of our patients reported an immunologic dysfunction supporting the previous report of an immunologic etiology of Classic Kaposi Sarcoma. ${ }^{15}$

In addition to the hematopoeitic malignancies, the Classic Kaposi Sarcoma population in this study had an increased incidence in urinary bladder carcinoma, laryngeal carcinoma, and nonmelanoma skin cancers compared to that expected based on SEER data. ${ }^{4}$ Among this Classic Kaposi Sarcoma group, there was a decrease in the incidence of lung cancer, supporting previous studies. ${ }^{9}$ Furthermore, despite the occurrence of HHV-8 in prostate specimens of healthy males and in the genitourinary tract of normal females, there was a decreased incidence in prostate carcinoma and female genital tract malignancies in these Classic Kaposi Sarcoma patients, comparable with previous reports. ${ }^{10,19,23}$ The reported increased risk of developing Classic Kaposi Sarcoma after breast carcinoma ${ }^{23}$ could not be substantiated in this study as only one patient had a history of breast carcinoma. This is likely a reflection of the previously noted lack of available slides and history from many of the females in our database. We also noted a slight decrease in pancreatic carcinomas over that expected in the general population. In the AIDS-related Kaposi Sarcoma group, there was a high incidence of anal carcinoma; this is related to HIV risk factors and was not present in any Classic Kaposi Sarcoma patients. One of the AIDS-related Kaposi Sarcoma patients had an angiosarcoma. However, of interest, none of our Classic Kaposi Sarcoma patients had another sarcoma, although Kaposi Sarcoma is considered to be a sarcoma itself, fibroblastic and vascular endothelial growth factors are thought to play a role in its development. ${ }^{10}$

The prognosis of Classic Kaposi Sarcoma alone is good; it is the associated malignancy that accounted for most deaths in our patients. Most Classic Kaposi Sarcoma patients $(n=382,79 \%)$ had solitary or multifocal lesions. Ten percent $(n=47)$ of the Classic Kaposi Sarcoma patients had multicentric disease, only $1.4 \%$ had visceral involvement, and less than $1 \%$ had disseminated disease. Of the patients with follow-up data available, $3.8 \%$ died from widespread visceral Kaposi Sarcoma or hemorrhagic complications, similar to previous reports. ${ }^{15}$ Comparatively, AIDS-related Kaposi Sarcoma is much more aggressive with $78 \%$ having multicentric disease, $12 \%$ with visceral involvement and $6 \%$ with widespread disseminated disease.

HHV-8, also known as Kaposi Sarcoma herpes virus, was first isolated in 1994 from Kaposi Sarcoma in an HIV + patient. ${ }^{11}$ It is most closely homologous to the gamma-herpes virus family, which includes Epstein-Barr virus, to which HHV8 is $39 \%$ homologous. ${ }^{31} \mathrm{HHV}-8$ is tightly connected as the etiologic agent in Kaposi Sarcoma with roles for the viral lytic gene and the lack of specific HHV-8 T-cell immune response in patients with Kaposi Sarcoma being recently documented. ${ }^{21,31-37}$ This virus induces cytokines, which are known to play a role in the development of Classic Kaposi Sarcoma. ${ }^{10,38}$ It is hypothesized that lymphoproliferative disorders or other malignancies might pass HHV-8 to its lytic phase, in sites of latency, ${ }^{39}$ and 


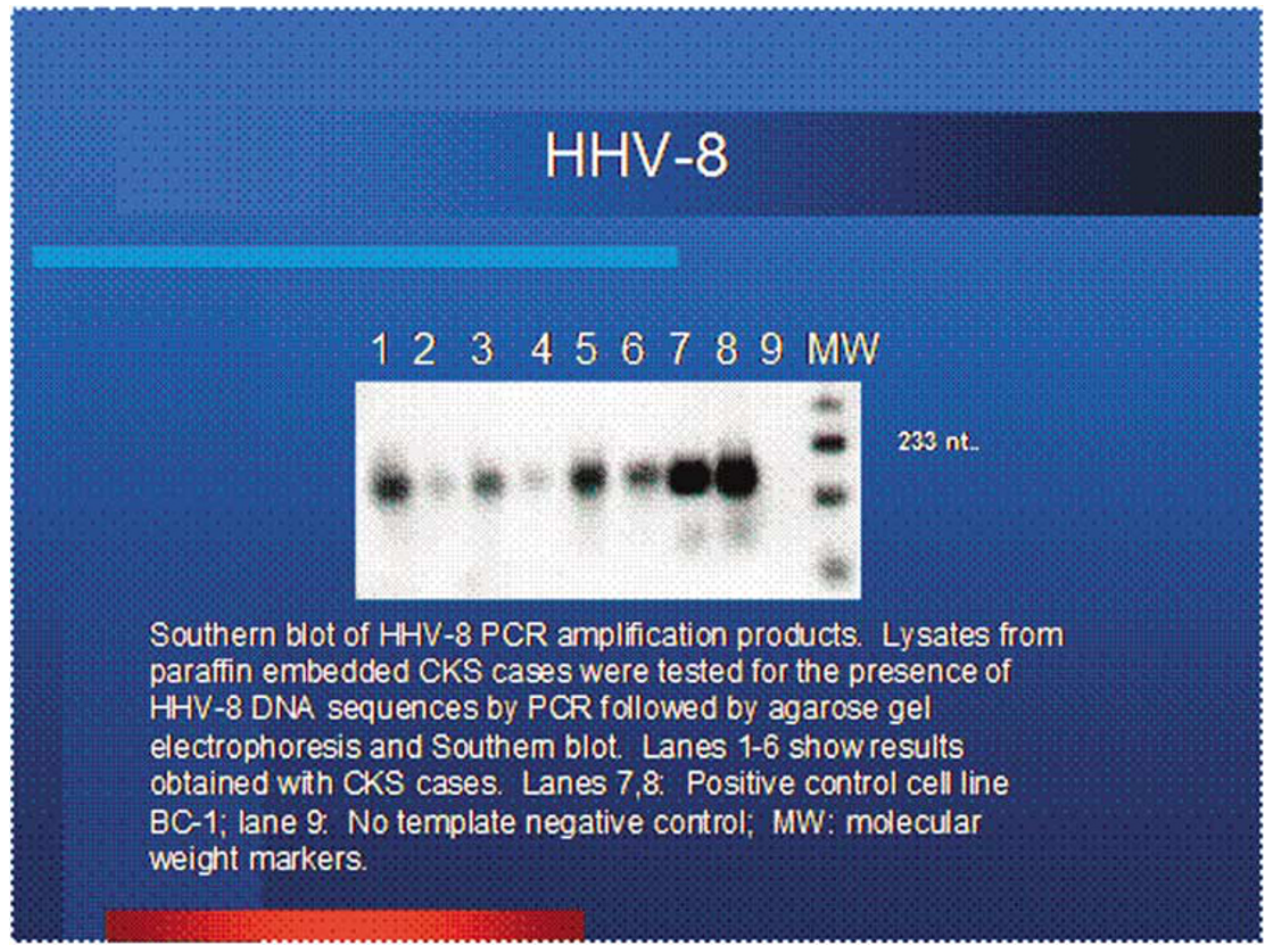

Figure 5 Southern blot of HHV8 PCR amplification products. Lysates from paraffin-embedded Classic Kaposi Sarcoma cases were tested for the presence of HHV8 DNA sequences by PCR followed by agarose gel electrophoresis and Southern blot. Lanes 1-6 show results obtained with Classic Kaposi Sarcoma cases. Lanes 7, 8: positive control cell line BC-1; lane 9: no template negative control; MW: molecular weight markers.

thus induce development of Classic Kaposi Sarcoma. Likewise, HIV-1 Tat, in AIDS-related Kaposi Sarcoma, promotes the growth of spindle cells of endothelial origin in the presence of inflammatory cytokines. ${ }^{40}$

Although the majority of our subgroup of Classic Kaposi Sarcoma patients, representing a cross-section oflesional stage and patient gender, were positive by PCR analysis for HHV-8, one case with ample material was negative. These data are consistent with the findings of other published studies on the incidence of HHV-8 in Kaposi Sarcoma. This observation is consistent with the findings of other published studies on the incidence of HHV-8 in Kaposi Sarcoma, which, in general, report detection of the virus in nearly all, but not quite $100 \%$, of cases examined. ${ }^{39,41}$ In some cases, the failure to detect the virus may be related to low viral copy number. Chang et $a l^{11}$ were able to identify viral sequences in only $74 \%$ of AIDS Kaposi Sarcoma specimens by Southern blot, whereas $93 \%$ were positive by PCR. Viral copy number may be lower in Classic Kaposi Sarcoma as compared to Aids Kaposi Sarcoma, a possibility supported by one study that found $100 \% \quad(n=13)$ of AIDS Kaposi Sarcoma samples but only $72 \%(13 / 18)$ of Classic Kaposi Sarcoma cases were PCR positive for the virus. ${ }^{41}$ Another possible explanation of the rare negative cases is sequence polymorphisms within the primer binding sites, which would preclude detection by
PCR. Finally, it remains possible that rare cases of Kaposi Sarcoma do not contain the virus.

Although the incidence of AIDS-associated Kaposi Sarcoma has decreased with the introduction of highly active antiretroviral therapy, it is still the most common malignancy in the HIV-infected population. ${ }^{42,43}$ The disease is much more aggressive than Classic Kaposi Sarcoma, probably due to the synergism of HIV-1 and HHV-8 and the greater level of immune suppression in AIDS patients. Homosexual men with AIDS (in the United States) have a 100000 -fold increased risk for Kaposi Sarcoma compared to the general population and are more than twice as likely to develop Kaposi Sarcoma as those who acquire HIV by other routes of transmission. ${ }^{44}$ The anatomic distribution is more wide spread in AIDS-associated Kaposi Sarcoma ${ }^{45}$ and is more frequently multifocal and visceral than in Classic Kaposi Sarcoma.

With regards to the histologic differential diagnosis of Kaposi Sarcoma, the contributing pathologists diagnosed the majority of our cases Classic Kaposi Sarcoma correctly. Other lesions in the differential diagnosis included other vascular lesions and various fibrohistiocytic lesions. In general, Classic Kaposi Sarcoma, especially in its nodular phase, was not difficult to diagnose. Several biases need to be taken into consideration in the conclusions drawn from this study. All cases were sent as a referral for a second opinion. As compared 
Table 6 Associated malignancies in CKS patients (A), compared with the expected malignancies in the general population (B)

\begin{tabular}{|c|c|c|c|c|c|}
\hline $\begin{array}{l}\text { (A) } \\
\text { Malignancy }\end{array}$ & $\begin{array}{l}\text { Expected/100 000/ } \\
\text { yr } 65 \text { and over (SEER } \\
\text { except as noted) }\end{array}$ & $\begin{array}{c}\text { Observed } \\
\text { number of cases/ } \\
108 \text { pt/20 year }\end{array}$ & $\begin{array}{l}\text { Observed number } \\
\text { of cases } / 108 \\
\text { patient/year }\end{array}$ & $\begin{array}{c}\text { Expected number } \\
\text { of cases/108 } \\
\text { patient/year ** }\end{array}$ & $S I R * * *$ \\
\hline Prostate cancer & 1131.9 & 11 & 0.55 & 1.1 & 0.5 \\
\hline Lung carcinoma & 346.8 & 5 & 0.25 & 0.3 & 0.8 \\
\hline Multiple myeloma & 28.3 & 4 & 0.2 & 0.03 & $6.6^{*}$ \\
\hline Lymphoma & 77.0 & 4 & 0.2 & 0.08 & $2.5^{*}$ \\
\hline Colorectal carcinoma & 287.8 & 3 & 0.15 & 0.3 & 0.5 \\
\hline $\begin{array}{l}\text { Nonmelanoma skin cancer } \\
\text { (squamous cell and basal } \\
\text { cell carcinoma) }\end{array}$ & $233(1)$ & $11+3$ & 0.7 & 0.25 & $2.8^{*}$ \\
\hline Laryngeal carcinoma & 19.1 & 2 & 0.1 & 0.02 & $5^{*}$ \\
\hline Bladder carcinoma & 110.8 & 2 & 0.1 & 0.01 & $10^{*}$ \\
\hline Oral carcinoma & 44.2 & 1 & 0.05 & 0.04 & $1.25^{*}$ \\
\hline Gastric carcinoma & 44.1 & 1 & 0.05 & 0.04 & $1.25^{*}$ \\
\hline Breast & 258.5 & 1 & 0.05 & 0.03 & $1.7^{*}$ \\
\hline Renal cell carcinoma & 46.1 & 1 & 0.05 & 0.05 & 1 \\
\hline Melanoma & 45.5 & 1 & 0.05 & 0.05 & 1 \\
\hline Pancreatic & 59.1 & 1 & 0.05 & 0.06 & 0.8 \\
\hline Brain and other nervous system & 19.1 & 0 & 0 & 0.02 & 0 \\
\hline Carcinoid & $1.2-1.9(2)$ & 1 & 0.05 & $<0.01$ & $5^{*}$ \\
\hline
\end{tabular}

(B)

\section{Associated malignancies in CKS patients}

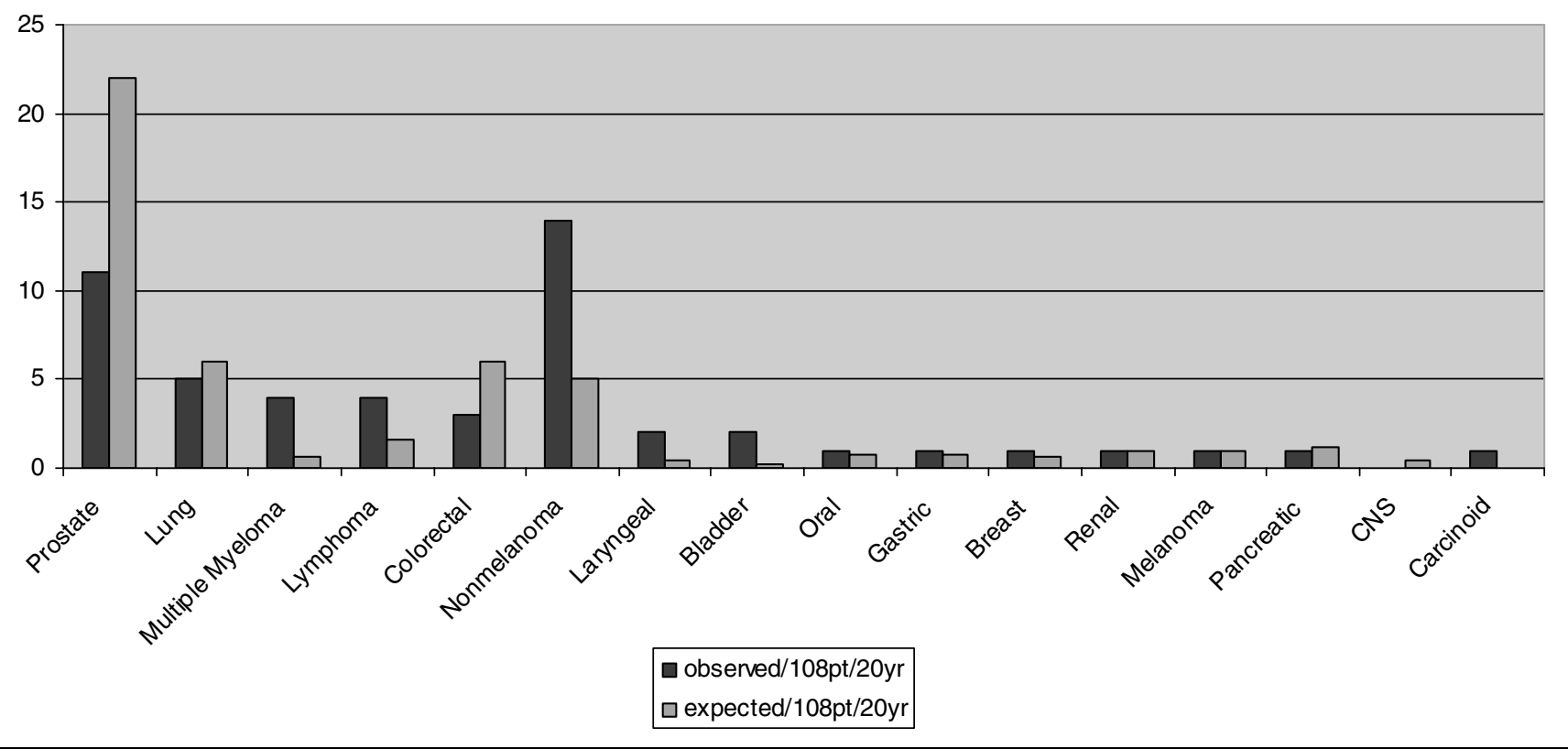

Rates are available for whites only, nonwhite populations have incidence rates $<2 \%$ of the rates among whites. ${ }^{42}$

Modlin. ${ }^{31}$

*Higher incidence than expected.

**Based on Incidence rates for 65 and over, both sexes, all races, SEER Cancer Statistics Review 1973-1996, NCI.

$* * * \mathrm{SIR}=$ standardized incidence ratio (observed/expected).

to the male patients, slides from a smaller fraction of the female patients were available for review and follow-up resulting in a male bias. AIDS-related Kaposi Sarcoma was less commonly seen at our institution over that last two decades than Classic Kaposi Sarcoma, possibly because pathologists may be more comfortable making a diagnosis of Kaposi Sarcoma in the setting of AIDS/HIV than in an elderly patient with no risk factors. The latter case is more likely to be sent for consultation.
In conclusion, Classic Kaposi Sarcoma is predominantly a disease of Caucasian/American, but also of Mediterranean, Hispanic, and Black males, involving the lower extremities, presenting in the nodular phase. Many of the patients have associated second malignancies, which may relate to the etiology of Classic Kaposi Sarcoma. Ninety-eight percent of Classic Kaposi Sarcoma cases with ample material, even in the patch stage, were positive for HHV-8 by PCR. In comparison, AIDS-related Kaposi 
Table 7 Clinical follow up of CKS patients

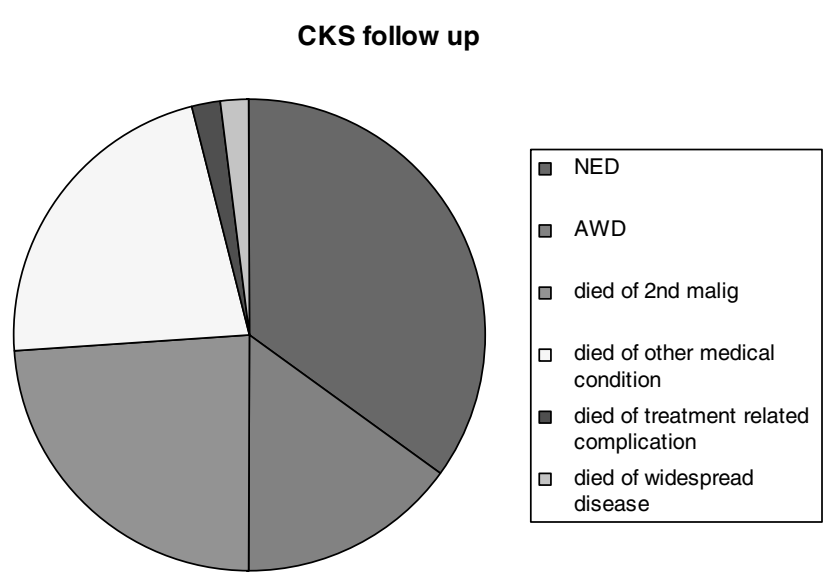

Sarcoma is found in a younger, more male predominant group with a different ethnic or racial and site distribution than Classic Kaposi Sarcoma, relating to its risk factors. Furthermore, AIDS-related Kaposi Sarcoma is more aggressive than Classic Kaposi Sarcoma, as it is predominately multifocal, and has higher rates of visceral involvement, dissemination, and death from disease. Although disease may persist, Classic Kaposi Sarcoma by itself is rarely the cause for the patient's demise.

\section{References}

1 Cox FH, Helwig EB. Kaposi's sarcoma. Cancer 1959;12:289-298.

2 Smith KJ, Nelson A, Angritt P, et al. Kaposi's sarcoma in women: a clinicopathologic study. J Cutan Med Surg 1999;3:132-139.

3 Weiss SW, Goldblum JR. Malignant vascular tumors. Enzinger and Weiss's Soft Tissue Tumors 1995, Mosby: St Louis, MO, 641-677.

4 Ries LAG, Eisner MP, Kosary CL, et al. Seer Cancer Statistics Review, 1973-1997. National Cancer Institute: Bethesda, MD, 2000.

5 Lichy JH, Zavar M, Tsai MM. et al. Loss of heterozygosity on chromosome 11p15 during histological progression in microdissected ductal carcinoma of the breast. Am J Pathol 1998;153:271-278.

6 Kaloterakis A, Papasteriades C, Filiotou A, et al. Hla in familial and nonfamilial Mediterranean Kaposi's sarcoma in Greece. Tissue Antigens 1995;45:117-119.

7 Kaposi M. Idiopathisches multiples pigmentsarom der haut. Arch f Dermatol u Syph 1872;3:265-273.

8 Ascoli V, Belli S, Benedetti M, et al. High incidence of classic Kaposi's sarcoma in Mantua, Po Valley, Northern Italy (1989-1998). Br J Cancer 2001;85:379-382.

9 Iscovich J, Boffetta P, Brennan P. Classic Kaposi's sarcoma as a first primary neoplasm. Int J Cancer 1999;80:173-177.
10 Iscovich J, Boffetta P, Franceschi S, et al. Classic Kaposi sarcoma: epidemiology and risk factors. Cancer 2000;88:500-517.

11 Chang Y, Cesarman E, Pessin MS, et al. Identification of herpesvirus-like DNA sequences in AIDS-associated Kaposi's sarcoma. Science 1994;266:1865-1869.

12 Lebbe C, Agbalika F, de Cremoux P, et al. Detection of human herpesvirus 8 and human t-cell lymphotropic virus type 1 sequences in Kaposi sarcoma. Arch Dermatol 1997;133:25-30.

13 Kao GF, Johnson FB, Sulica VI. The nature of hyaline (eosinophilic) globules and vascular slits of Kaposi's sarcoma. Am J Dermatopathol 1990;12:256-267.

14 Biggar RJ, Curtis RE, Cote TR, et al. Risk of other cancers following Kaposi's sarcoma: relation to acquired immunodeficiency syndrome. Am J Epidemiol 1994;139:362-368.

15 Fenig E, Brenner B, Rakowsky E, et al. Classic Kaposi sarcoma: experience at Rabin Medical Center in Israel. Am J Clin Oncol 1998;21:498-500.

16 Hjalgrim H, Frisch M, Pukkala E, et al. Risk of second cancers in classical Kaposi's sarcoma. Int J Cancer 1997;73:840-843.

17 Stratigos JD, Potouridou I, Katoulis AC, et al. Classic Kaposi's sarcoma in Greece: a clinico-epidemiological profile. Int J Dermatol 1997;36:735-740.

18 Franceschi S, Arniani S, Balzi D, et al. Survival of classic Kaposi's sarcoma and risk of second cancer. Br J Cancer 1996;74:1812-1814.

19 Monini P, de Lellis L, Fabris M, et al. Kaposi's sarcomaassociated herpesvirus DNA sequences in prostate tissue and human semen. N Engl J Med 1996;334: 1168-1172.

20 Friedman-Birnbaum R, Weltfriend S, Katz I. Kaposi's sarcoma: Retrospective study of 67 cases with the classical form. Dermatologica 1990;180:13-17.

21 Safai B, Mike V, Giraldo G, et al. Association of Kaposi's sarcoma with second primary malignancies: possible etiopathogenic implications. Cancer 1980;45: 1472-1479.

22 Sjak-Shie NN, Vescio RA, Berenson JR. The role of human herpesvirus-8 in the pathogenesis of multiple myeloma. Hematol Oncol Clin North Am 1999;13: 1159-1167.

23 Iscovich J, Boffetta P, Winkelmann R, et al. Classic Kaposi's sarcoma as a second primary neoplasm. Int J Cancer 1999;80:178-182.

24 Ablashi DV, Chatlynne L, Thomas D, et al. Lack of serologic association of human herpesvirus-8 (Kaposi Sarcomahv) in patients with monoclonal gammopathy of undetermined significance with and without progression to multiple myeloma. Blood 2000;96:2304-2306.

25 Cesarman E, Chang Y, Moore PS, et al. Kaposi's sarcomaassociated herpesvirus-like DNA sequences in aids-related body-cavity-based lymphomas. N Engl J Med 1995;332:1186-1191.

26 Hjalgrim H, Frisch M, Melbye M. Incidence rates of classical Kaposi's sarcoma and multiple myeloma do not correlate. Br J Cancer 1998;78:419-420.

27 Moore PS, Kingsley LA, Holmberg SD, et al. Kaposi's sarcoma-associated herpesvirus infection prior to onset of Kaposi's sarcoma. AIDS 1996;10:175-180.

28 Rettig MB, Ma HJ, Vescio RA, et al. Kaposi's sarcomaassociated herpesvirus infection of bone marrow dendritic cells from multiple myeloma patients. Science 1997;276:1851-1854. 
29 Soulier J, Grollet L, OKaposi Sarcomaenhendler E, et al. Kaposi's sarcoma-associated herpesvirus-like DNA sequences in multicentric castleman's disease. Blood 1995;86:1276-1280.

30 Gao SJ, Alsina M, Deng JH, et al. Antibodies to Kaposi's sarcoma-associated herpesvirus (human herpesvirus 8) in patients with multiple myeloma. J Infect Dis 1998;178:846-849.

31 Moore PS, Gao SJ, Dominguez G, et al. Primary characterization of a herpesvirus agent associated with Kaposi's sarcomae. J Virol 1996;70:549-558.

32 Levy JA. A new human herpesvirus: Kaposi Sarcomahv or HHV8? Lancet 1995;346:786.

33 Neipel F, Albrecht JC, Fleckenstein B. Cell-homologous genes in the Kaposi's sarcoma-associated rhadinovirus human herpesvirus 8: determinants of its pathogenicity? J Virol 1997;71:4187-4192.

34 Roizman B. New viral footprints in Kaposi's sarcoma. N Engl J Med 1995;332:1227-1228.

35 Russo JJ, Bohenzky RA, Chien MC, et al. Nucleotide sequence of the Kaposi sarcoma-associated herpesvirus (HHV8). Proc Natl Acad Sci USA 1996;93: 14862-14867.

36 Yarchoan R. Key role for a viral lytic gene in Kaposi’s sarcoma. N Engl J Med 2006;355:1383-1385.

37 Guihot A, Dupin N, Marcelin AG, et al. Low t cell responses to human herpesvirus 8 in patients with aids-related and classic Kaposi sarcoma. J Infect Dis 2006;194:1078-1088.
38 Dezube BJ. The role of human immunodeficiency virus-i in the pathogenesis of acquired immunodeficiency syndrome-related Kaposi's sarcoma: the importance of an inflammatory and angiogenic milieu. Semin Oncol 2000;27:420-423.

39 Fossati S, Boneschi V, Ferrucci S, et al. Human immunodeficiency virus negative Kaposi sarcoma and lymphoproliferative disorders. Cancer 1999;85:1611-1615.

40 Ensoli B, Barillari G, Salahuddin SZ, et al. Tat protein of HIV-1 stimulates growth of cells derived from Kaposi's sarcoma lesions of AIDS patients. Nature 1990;345:84-86.

41 Rady PL, Yen A, Martin III RW, et al. Herpesvirus-like DNA sequences in classic Kaposi's sarcomas. J Med Virol 1995;47:179-183.

42 Jones JL, Hanson DL, Dworkin MS, et al. Incidence and trends in Kaposi's sarcoma in the era of effective antiretroviral therapy. J Acquir Immune Defic Syndr 2000;24:270-274.

43 Cannon M, Cesarman E. Kaposi's sarcoma-associated herpes virus and acquired immunodeficiency syndrome-related malignancy. Semin Oncol 2000;27: 409-419.

44 Goedert JJ. The epidemiology of acquired immunodeficiency syndrome malignancies. Semin Oncol 2000;27:390-401.

45 Dezube BJ. Acquired immunodeficiency syndromerelated Kaposi's sarcoma: clinical features, staging, and treatment. Semin Oncol 2000;27:424-430. 